\section{Senescence of Daffodil (Narcissus pseudonarcissus) Cut Flowers treated with Benzyladenine and Auxin}

ONE of the kinins, benzyladenine (BA), has been reported to retard the senescence of cut flowers of carnations $^{1}$ and King Alfred daffodils after the daffodils have been stored for two weeks at $0.5^{\circ} \mathrm{C}$ (ref. 2). Later it was found that BA was ineffective on freshly-cut daffodils. In the experiment described below, BA was combined with various concentrations of the sodium salt of 2,4 dichlorophenoxyacetic acid (2,4-D). Both 2,4-D and $\mathrm{BA}$ have been reported to be effective in delaying the senescence of cauliflower ${ }^{3}$.

Flowers of field-grown King Alfred daffodils were cut April 3, 1964, and floral parts only were dipped for $5 \mathrm{sec}$ in combinations of 0 and $5 \times 10^{-4} \mathrm{M} \mathrm{BA}$ and $0,10^{-5}, 10^{-4}$ and $10^{-3} \mathrm{M} 2,4-\mathrm{D}$. Each solution contained $0 \cdot 1$ per cent 'Tween 20' (sorbitan polyoxyethylene monolaurate). Each treatment was repeated four times and each repeat consisted of three flowers. The stems of these flowers were placed in tap water at a room temperature of $22^{\circ}$ C. The replicates were arranged according to a completely randomized design ${ }^{4}$.

Fresh weights of the perianth segments were determined 5 and 6 days after treatment because a loss of fresh weight had previously been found to accompany senescence of cut King Alfred daffodil flowers. Dry weights were made 6 days after treatment to determine the relative importance of water loss. Differences between means were tested by Duncan's multiple range test ${ }^{5}$.

Freshly cut King Alfred daffodils may be preserved by a combination of $5 \times 10^{-4} \mathrm{M} \mathrm{BA}$ and $10^{-4} \mathrm{M} 2,4-\mathrm{D}$, but not by BA or 2,4-D alone (Table 1). The preserved flowers were obviously alive and turgid. Flowers treated with $10^{-3} \mathrm{M}$ 2,4-D had badly twisted perianth segments, but flowers dipped in $10^{-4}$ 2,4-D did not begin to twist until 6 days after treatment. At this time, their commercial life was terminated despite the fact that they were turgid, with fow markings. The successful $\mathrm{BA}-2,4-\mathrm{D}$ treatments affected the dry weights of the perianth segments very little compared with their marked effect on fresh weights (Table 1). Senescence in daffodils is probably due, at least in part, to a dehydration of the flower. Flowers treated with $5 \times 10^{-4} \mathrm{M} \mathrm{BA}$ and $10^{-4} \mathrm{M}$ or $10^{-3} \mathrm{M}$ 2,4-D contained more water than did the checks (Table 1). Water content was determined by subtracting dry weights from corresponding fresh weights.

Kaufman and Ringel found that treatment of cauliflower with 2,4-D retarded abscission and treatment with $\mathrm{BA}$ retarded yellowing ${ }^{3}$. The experiment reported here does not indicate whether each chemical has a separate function or not. There is definite indication that both $\mathrm{BA}$ and 2,4-D must be present to prevent a dehydra. OF PERIANTH SEgMants of King ALFred DAFFodits TREATED WITH BENZYLADENINE (BA) AND 2,4-DICHLOROPHENOXY ACETIO ACID $(2,4-D)$

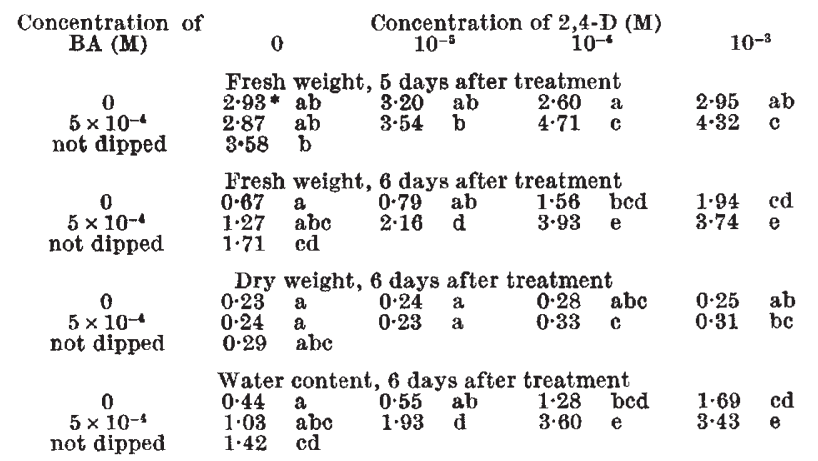
* Mean of 4 replications each consisting of perianth segments of three
flowers. All means followed by the same letter are not significantly different at the 1 per cent level. tion and ageing of perianth segments of freshly cut daffodils.

Previously, I found that BA preserved daffodil flowers if it was applied after the flowers had been stored at $0.5^{\circ} \mathrm{C}$ for two weeks ${ }^{2}$. BA alone is ineffective on freshly cut daffodils. The condition of the flower when treated may determine the effectiveness of hormones applied as senescence retardants.

The commercial use of BA and 2,4-D must depend on the cost of BA, as yet available only for experimental purposes, and on the ease of application. A flower dip is not as commercially applicable as a stem dip. However, the movement of BA through plant tissues is primarily basipetally polar, and so cannot be used as a stem dip.

I thank Mr. G. A. Vantreight, Victoria, B.C., for the daffodils, and I also thank the Shell Oil Company of Canada, Ltd., for the benzyladenine used in this experiment. This work was supported by a research grant from the Faculty Research Fund of the University of Victoria.

\section{J. BaLlantyNE}

Department of Biology,

University of Victoria,

Victoria, B.C., Canada.

1 MacLean, D. C., and Dedolph, R. R., Bot. Gaz.,124, 20 (1962).

- Ballantyne, D. J Can. J Plant Sci, 43, 225 (1963)

${ }^{3}$ Kaufman, J., and Ringel, S. M., Proc. Amer. Soc. Hort. Sci, , 78, 349 (1961).

"Cochran, W. G., and Cox, G. M., Experimental Designs (John Wiley and Sons, Inc., New York, 1957)

${ }^{5}$ Duncan, D. B., Biometrics, 11, 1 (1955).

Osborne, D. J., and Black, M. K., Nature, 201, 97 (1964).

\section{Effects of Nutritional Treatments of Seed- bearing Plants on the Performance of their Progeny}

HARRINGToN ${ }^{1}$ collected seod from carrot, lettuce and pepper plants showing severe deficiencies of several major nutrients and found that the deficiencies had little effect on the percentage germination of the seed. Szukalski ${ }^{2}$ applied different amounts of a phosphorus fertilizer to flax and rape plants and showed that when seed from these plants was sown in phosphorus-deficient soil, high levels of phosphorus in the seed were advantageous for seedling growth. Results from Durrant's $\mathrm{s}^{\mathbf{3}}$ experiments with flax indicated that nutritional treatments given to flax plants brought about apparently heritable changes. In the present experiments nutritional treatments were applied to watercress, pea and carrot plants and plants from their seed were raised to determine the effects of the seed-plant treatments on the progenies. This communication gives a report of the results obtained.

In experiments with watercress (Rorippa nasturtium aquaticum L., Hayek) seed was harvested from plants grown in sand cultures supplied with Hewitt's nutrient solution modified to contain either $0.2,1.0$ or 4.0 m.equiv. 1. phosphorus (as ortho-phosphate). Iron was supplied chelated with ethylenediamine tetraacetic acid. Seed from plants grown under the three culture treatments (called $P_{1}, P_{2}$ and $P_{3}$ seed) had, respectively, $0.47,0.84$ and 0.95 per cent of their dry weight as phosphorus, while differences in their contents of nitrogen and potassium were slight. These seeds were all similar in size and, two months after harvest, all had a germination of more than 90 per cent. The three kinds of seed were then sown in cultures supplied with each of the three solutions, and plant weights were determined after 7-9 weeks of growth. In cultures with the lowest level of phosphorus, plants from $P_{1}, P_{2}$ and $P_{\mathrm{s}}$ seed had a mean dry weight of $0.095 \mathrm{~g}$, $0.139 \mathrm{~g}$ and $0.181 \mathrm{~g}$, respectively (L.S.D. 0.0252). At the higher levels of phosphorus supply, plant weights did not reflect differences in the phosphorus content of the seed. In further experiments it was found that none of the effects produced by treatments applied to a first 